\title{
Clinical outcome of advanced and metastatic renal cell carcinoma treated with targeted therapy: is there a difference between young and old patients?
}

This article was published in the following Dove Press journal:

OncoTargets and Therapy

3 November 2014

Number of times this article has been viewed

\author{
Guiming Zhang ${ }^{1,2, *}$ \\ Yao Zhu' ${ }^{1,2, *}$ \\ Dahai Dong ${ }^{3}$ \\ Weijie $\mathrm{Gu}^{1,2}$ \\ Hailiang Zhang ${ }^{1,2}$ \\ Lijiang Sun ${ }^{3}$ \\ Dingwei $\mathrm{Ye}^{1,2}$
}

\begin{abstract}
'Department of Urology, Fudan University Shanghai Cancer Center, Shanghai, People's Republic of China; ${ }^{2}$ Department of Oncology, Shanghai Medical College, Fudan University, Shanghai, People's Republic of China; ${ }^{3}$ Department of Urology, The Affiliated Hospital of Qingdao University,

Qingdao, People's Republic of China

*These authors contributed equally to this work
\end{abstract}

Correspondence: Lijiang Sun Department of Urology, The Affiliated Hospital of Qingdao University, No 16, Jiangsu Road, Qingdao, Shandong, 266003, People's Republic of China

Tel +86 532829 I 1329

Fax +86 532 829। 1999

Email slijiang999@।26.com

Correspondence: Dingwei Ye Department of Urology, Fudan University Shanghai Cancer Center, No 270, Dongan Road, Shanghai, 200032, People's Republic of China Tel +86 2I 64175590 Fax +86 21 64438640 Email dwyeli@163.com
Background: To assess whether the clinical outcome of advanced and metastatic renal cell carcinoma (mRCC) treated with targeted therapy differs between young and old patients.

Patients and methods: A total of 327 patients with advanced renal cell carcinoma and $\mathrm{mRCC}$ who received targeted therapy in two Chinese clinical centers were analyzed retrospectively. The patients were stratified into three groups: young (aged $<45$ years), middle-aged (aged $45-64$ years), and old (aged $\geq 65$ years). Overall survival (OS) and progression-free survival (PFS) curves were drawn using the Kaplan-Meier method, and Cox's proportional hazard regression model was used to compare OS and PFS within age groups.

Results: There were no significant differences among young, middle-aged, and old groups in terms of OS $(P=0.087)$, whereas PFS in the old group was significantly better than in the young and middle-aged groups $(P=0.043)$. Both OS and PFS in the younger groups (aged $<65$ years) were significantly worse than in the old group (age $\geq 65$ years; median OS, 28.1 vs 28.7 months $[P=0.029]$; median PFS, 11.4 vs 14 months $[P=0.015])$. No difference in OS or PFS was found between the young and middle-aged groups. After adjusting for sex, body mass index, smoking status, hypertension, diabetes mellitus, Eastern Cooperative Oncology Group score, history of cytokines, and Fuhrman grade, old age was an independent favorable prognostic factor for OS and PFS compared with younger age ( $<65$ years) (OS, hazard ratio, 0.552 [95\% confidence interval, 0.329-0.828; $P=0.006$ ]; PFS, hazard ratio, 0.584 [95\% confidence interval, $0.401-0.850$; $P=0.005])$.

Conclusion: Younger patients with advanced renal cell carcinoma and $\mathrm{mRCC}$ receiving targeted therapy have a poorer prognosis compared with old patients. These results remain to be examined in prospective cohorts.

Keywords: kidney cancer, metastasis, targeted therapy, prognosis, age

\section{Introduction}

Almost $20 \%-30 \%$ of patients present with metastasis at diagnosis of renal cell carcinoma ( $\mathrm{RCC}$ ), which is the third most prevalent urological malignancy. ${ }^{1}$ In addition, relapse and metastasis occur in $\sim 20 \%$ of RCC patients who have received surgical intervention. ${ }^{2}$ Before the era of targeted therapy, cytokines were the most commonly used agents once RCC patients showed distant metastasis; however, the effect was not satisfactory. ${ }^{3}$ Because targeted therapy has been approved for the treatment of metastatic RCC (mRCC), many patients have benefited from this dramatic paradigm shift and have shown improved clinical outcomes. 
RCC incidence is strongly related to age. An average of $75 \%$ of cases are diagnosed in those aged $\geq 60$ years, with a mean age of 63 years. ${ }^{4}$ At present, uncertainties still exist regarding the discrepancy of clinical characteristics between young and old RCC patients, as well as the prognostic effect of age on RCC. Several studies have pointed out that older age is correlated with higher TNM (tumor node metastasis) staging and pathological grade of RCC, suggesting an adverse association with prognosis..$^{5-7}$ Jun et al have reported that the incidence of high-grade RCC decreases as age increases. ${ }^{8}$ Similarly, another study has found that young RCC patients are more likely to present with unfavorable histological features and to develop metastasis. ${ }^{9}$ There are also reports that there is no difference in prognosis between young and old RCC patients. ${ }^{10,11}$

Given the diversity of pathological features among the different ages and the various comorbidities that old patients might experience, the difference in clinical outcomes between young and old RCC patients receiving targeted therapy remains a complex picture. To the best of our knowledge, research focusing on response to targeted therapy among RCC patients of different ages is currently lacking. Hutson and colleagues have reported that median progression-free survival (PFS) and overall survival (OS) are comparable in younger and older ( $\geq 70$ years) $\mathrm{mRCC}$ patients receiving sunitinib, suggesting that elderly patients may achieve additional clinical benefit. ${ }^{12}$ Similar results were found from the data of another group of patients treated with sorafenib. ${ }^{13}$ However, these two studies were conducted in white patients, and no studies have investigated whether there are different responses between young and old patients in the People's Republic of China. Here, we report a retrospective analysis in which the clinical outcomes of advanced RCC and $\mathrm{mRCC}$ treated with targeted therapy among different ages in two clinical centers in the People's Republic of China were compared.

\section{Patients and methods Study subjects}

This was a retrospective analysis of 327 consecutive patients with pathologically confirmed advanced RCC and mRCC between 2006 and February 2014 at the Department of Urology at Fudan University Shanghai Cancer Center and the Affiliated Hospital of Qingdao University. All information about age, sex, history of hypertension or diabetes mellitus, body mass index (BMI), smoking status, histology and staging, history of cytokines therapy, Eastern Cooperative Oncology Group performance status, and International Metastatic Renal-Cell
Carcinoma Database Consortium prognostic model was obtained from electronic records and medical charts. Protocols were approved by the Institutional Research Review Boards of the two clinical centers. All patients provided written informed consent before participation in the study.

The patients included those who received sorafenib or sunitinib as first-line targeted agents, which have been approved by the China Food and Drug Administration and are routinely used for mRCC treatment in the People's Republic of China. Efficacy endpoints included PFS and OS. PFS was defined as the time from receiving targeted therapy until disease progression (detected by radiology) or death (if death happened before progression). Adverse effects were recorded regularly.

\section{Exposure definition}

BMI is the patient's weight (in kilograms) divided by the height in square meters before treatment with targeted agents, and the threshold of overweight was $25 \mathrm{~kg} / \mathrm{m}^{2}$ or higher; smoking status (yes/no) represents current smokers or those who had ever smoked more than 100 cigarettes/year; hypertension was defined as 140 and $90 \mathrm{~mm} \mathrm{Hg}$ for systolic and diastolic blood pressure, respectively, on three consecutive occasions; and criteria of diabetes included $7.0 \mathrm{mmol} / \mathrm{L}$ or higher fasting serum glucose level or self-report of diabetes based on a physician's diagnosis.

\section{Statistical methods}

The patients were divided into three groups: young (aged $<45$ years), middle-aged (aged 45-64 years), and old (aged $\geq 65$ years). Categorical variables were expressed as frequencies and percentages, and $\chi^{2}$ tests were used to compare the difference. OS and PFS curves were drawn using the Kaplan-Meier method and were compared by log-rank test. Cox's proportional hazard regression model was used to evaluate the relationships among OS, PFS, and previously identified clinical variables such as age, sex, BMI, history of hypertension or diabetes, smoking status, stage, Fuhrman grade, pathologic type, and International Metastatic RenalCell Carcinoma Database Consortium model. Statistical significance was based on two-sided $P$ values lower than 0.05 . SPSS version 20.0 software (IBM Corporation, Somers, NY, USA) was used for statistical analyses.

\section{Results}

The study included 327 advanced RCC and mRCC patients whose demographic and clinical characteristics, stratified by age group, are shown in Table 1 . Among all the patients, 
Table I Demographic and clinical characteristics stratified by age in advanced and metastatic renal cell carcinoma patients

\begin{tabular}{|c|c|c|c|c|c|}
\hline Variables & $\begin{array}{l}\text { Total }(n=327) \\
n(\%)\end{array}$ & $\begin{array}{l}\text { Young ( }<45 \text { years) } \\
(\mathrm{n}=52), \mathrm{n}(\%)\end{array}$ & $\begin{array}{l}\text { Middle-aged (45-64 years) } \\
(\mathrm{n}=192), \mathrm{n}(\%)\end{array}$ & $\begin{array}{l}\text { Old }(\geq 65 \text { years }) \\
(n=83), n(\%)\end{array}$ & $P$-value \\
\hline \multicolumn{6}{|l|}{ Sex } \\
\hline Male & $242(74.0)$ & $30(57.7)$ & $142(74.0)$ & $70(84.3)$ & 0.003 \\
\hline Female & $85(26.0)$ & $22(42.3)$ & $50(26.0)$ & $13(15.7)$ & \\
\hline Body mass index, $\mathrm{kg} / \mathrm{m}^{2}$ & & & & & 0.783 \\
\hline$<25$ & 233 (7I.3) & $38(73.1)$ & $134(69.8)$ & $6 I(73.5)$ & \\
\hline$\geq 25$ & 94 (28.7) & $14(26.9)$ & $58(30.2)$ & $22(26.5)$ & \\
\hline Smoking status & & & & & 0.208 \\
\hline Yes & $110(33.6)$ & $13(25.0)$ & $64(33.3)$ & $33(39.8)$ & \\
\hline No & $217(66.4)$ & $39(75.0)$ & $128(66.7)$ & $50(60.2)$ & \\
\hline Hypertension & & & & & 0.284 \\
\hline Yes & $120(36.7)$ & $16(30.8)$ & $68(35.4)$ & $36(43.4)$ & \\
\hline No & $207(63.3)$ & $36(69.2)$ & $124(64.6)$ & $47(56.6)$ & \\
\hline Diabetes & & & & & 0.622 \\
\hline Yes & $60(18.3)$ & $12(23.1)$ & $34(17.7)$ & $14(16.9)$ & \\
\hline No & $267(81.7)$ & 40 (76.9) & $158(82.3)$ & $69(83.1)$ & \\
\hline History of cytokines therapy & & & & & 0.850 \\
\hline Yes & $89(27.2)$ & I5 (28.8) & $50(26.0)$ & $24(28.9)$ & \\
\hline No & $238(72.8)$ & 37 (7I.2) & $142(74.0)$ & $59(7 I .1)$ & \\
\hline Eastern Cooperative Oncology Group score & & & & & 0.009 \\
\hline 0 & $274(83.8)$ & $52(100.0)$ & I57 (8I.8) & $65(78.3)$ & \\
\hline 1 & $47(14.4)$ & $0(0)$ & $32(16.7)$ & $15(18.1)$ & \\
\hline 2 & $6(1.8)$ & $0(0)$ & $3(1.5)$ & $3(3.6)$ & \\
\hline International Metastatic Renal-Cell & & & & & 0.683 \\
\hline \multicolumn{6}{|l|}{ Carcinoma Database Consortium category } \\
\hline Favorable & $87(26.6)$ & $12(23.1)$ & $56(29.2)$ & $19(22.9)$ & \\
\hline Intermediate & $222(67.9)$ & $38(73.1)$ & $126(65.6)$ & $58(69.9)$ & \\
\hline Poor & $18(5.5)$ & $2(3.8)$ & $10(5.2)$ & $6(7.2)$ & \\
\hline Pathologic type & & & & & 0.149 \\
\hline Clear cell RCC & $293(89.6)$ & $42(80.8)$ & I7I (89.1) & $80(96.4)$ & \\
\hline Papillary RCC & $16(4.9)$ & $4(7.7)$ & II (5.7) & $\mathrm{I}(\mathrm{I} .2)$ & \\
\hline Chromophobe RCC & $3(0.9)$ & I (I.9) & $2(1.0)$ & $0(0)$ & \\
\hline Other & $15(4.6)$ & $5(9.6)$ & $8(4.2)$ & $2(2.4)$ & \\
\hline Stage & & & & & 0.539 \\
\hline III & $5(1.5)$ & $0(0)$ & $3(1.6)$ & $2(2.4)$ & \\
\hline IV & $322(98.5)$ & $52(100)$ & $189(98.4)$ & $81(97.6)$ & \\
\hline Fuhrman grade & & & & & $0.47 \mid$ \\
\hline I & $7(2.1)$ & I (I.9) & $4(2.1)$ & $2(2.4)$ & \\
\hline 2 & $61(18.7)$ & $7(\mid 3.5)$ & $31(16.1)$ & $23(27.7)$ & \\
\hline 3 & $101(30.9)$ & $17(32.7)$ & $59(30.7)$ & $25(30.1)$ & \\
\hline 4 & $86(26.3)$ & $14(26.9)$ & $56(29.2)$ & $16(19.3)$ & \\
\hline Missing & $72(22.0)$ & $13(25.0)$ & $42(21.9)$ & $17(20.5)$ & \\
\hline \multicolumn{6}{|l|}{ Metastatic site } \\
\hline Lung & $211(64.5)$ & $24(46.2)$ & $|3|(68.2)$ & $56(67.5)$ & 0.010 \\
\hline Bone & $81(24.8)$ & $9(17.3)$ & $5 I(26.6)$ & $21(25.3)$ & 0.387 \\
\hline Liver & $26(8.0)$ & $7(13.5)$ & $12(6.3)$ & $7(8.4)$ & 0.230 \\
\hline Other & $68(20.8)$ & $12(23.1)$ & $33(17.2)$ & $23(27.7)$ & 0.129 \\
\hline First-line targeted agents & & & & & 0.186 \\
\hline Sorafenib & $187(57.2)$ & $26(50.0)$ & $107(55.7)$ & $54(65.0)$ & \\
\hline Sunitinib & $140(42.8)$ & $26(50.0)$ & $85(44.3)$ & $29(35.0)$ & \\
\hline Second-line targeted agents & $48(14.7)$ & $14(26.9)$ & $25(13.0)$ & $9(10.8)$ & \\
\hline Sorafenib & $9(2.8)$ & $3(5.8)$ & $4(2.1)$ & $2(2.4)$ & 0.345 \\
\hline Sunitinib & II (3.4) & $4(7.7)$ & $5(2.6)$ & $2(2.4)$ & 0.168 \\
\hline Axitinib & $9(2.8)$ & I (I.9) & $7(3.6)$ & $\mathrm{I}(\mathrm{I} .2)$ & 0.485 \\
\hline Everolimus & $19(5.8)$ & $6(11.5)$ & $9(4.7)$ & $4(4.8)$ & 0.157 \\
\hline \multicolumn{6}{|l|}{ Adverse effects } \\
\hline Fatigue & $216(66.1)$ & $30(57.7)$ & $133(69.3)$ & $53(63.9)$ & 0.261 \\
\hline Hand-foot syndrome & $187(57.2)$ & $33(63.5)$ & $115(59.9)$ & $39(47.0)$ & 0.085 \\
\hline
\end{tabular}


Table I (Continued)

\begin{tabular}{|c|c|c|c|c|c|}
\hline Variables & $\begin{array}{l}\text { Total }(n=327) \\
\text { n }(\%)\end{array}$ & $\begin{array}{l}\text { Young ( }<45 \text { years) } \\
(n=52), n(\%)\end{array}$ & $\begin{array}{l}\text { Middle-aged ( } 45-64 \text { years) } \\
(n=192), n(\%)\end{array}$ & $\begin{array}{l}\text { Old ( } \geq 65 \text { years) } \\
(n=83), n(\%)\end{array}$ & $P$-value \\
\hline Diarrhea & $142(43.4)$ & $19(36.5)$ & $85(44.3)$ & $38(45.8)$ & 0.536 \\
\hline Nausea & $125(38.2)$ & $20(38.5)$ & 7II (37.0) & $34(4 I .0)$ & 0.822 \\
\hline Rash & I I 6 (35.5) & $19(36.5)$ & 65 (33.9) & $32(38.6)$ & 0.745 \\
\hline Hypertension & $82(25.1)$ & II (2I.2) & $46(24.0)$ & $25(30.1)$ & 0.432 \\
\hline Alopecia & 78 (23.9) & I 5 (28.8) & $43(22.4)$ & $20(24.1)$ & 0.625 \\
\hline Anemia & $46(14.1)$ & $6(11.5)$ & $25(13.0)$ & $15(18.1)$ & 0.461 \\
\hline
\end{tabular}

Note: $P$-values less than 0.05 are shown in bold.

Abbreviation: RCC, renal cell carcinoma.

59 cases were pathologically confirmed by percutaneous renal biopsy, 137 cases received palliative nephrectomy, and 131 cases manifested metastases after surgical resection of renal tumors, of which two patients received partial nephrectomy and 129 patients received radical nephrectomy. Sorafenib and sunitinib were taken as the first-line targeted agents. Once the first-line therapy failed, either switching among first-line drugs or other second-line targeted agents, including axitinib and everolimus, were used in 48 patients.

The most common adverse effects were fatigue, handfoot syndrome, diarrhea, nausea, and rash, which indicated no significant difference in incidence among groups (Table 1). There were seven patients (no young patients, three middleaged patients, and four old patients) permanently discontinuing targeted therapy as a result of intolerable adverse effects during the follow-up of 3-80 months (median, 28.4 months).

First, we compared the difference in OS and PFS among the young, middle-aged, and old groups. As shown in Figure 1A, there were no significant differences among the young, middle-aged, and old groups in terms of OS
( $P=0.087)$, whereas PFS in the old group was significantly better than that in the young and middle-aged groups ( $P=0.043$ ) (Figure 1B). We combined the young and young and middle-aged groups (named "younger group") and found that both OS and PFS in the younger group were significantly worse than the corresponding values in the old group (median OS, 28.1 vs 28.7 months [ $P=0.029$ ]; median PFS, 11.4 vs 14 months $[P=0.015]$ ) (Figure $2 \mathrm{~A}$ and $\mathrm{B}$ ). Next, we compared OS and PFS in young and middle-aged patients and found no difference between these two groups (Figure 3A and B). In addition, the difference of demographic and clinicopathological characteristics between these two groups is listed in the supplementary Table.

We then assessed the effect of old age on OS and PFS, using Cox's proportional hazard regression model, as summarized in Table 2. After adjusting for sex, BMI, smoking status, hypertension, diabetes, Eastern Cooperative Oncology Group score, history of cytokines, and Fuhrman grade, old age ( $\geq 65$ years) was an independent favorable prognostic factor for both OS and PFS compared with younger age $(<65$ years) (OS: hazard ratio, $0.552[95 \%$ confidence
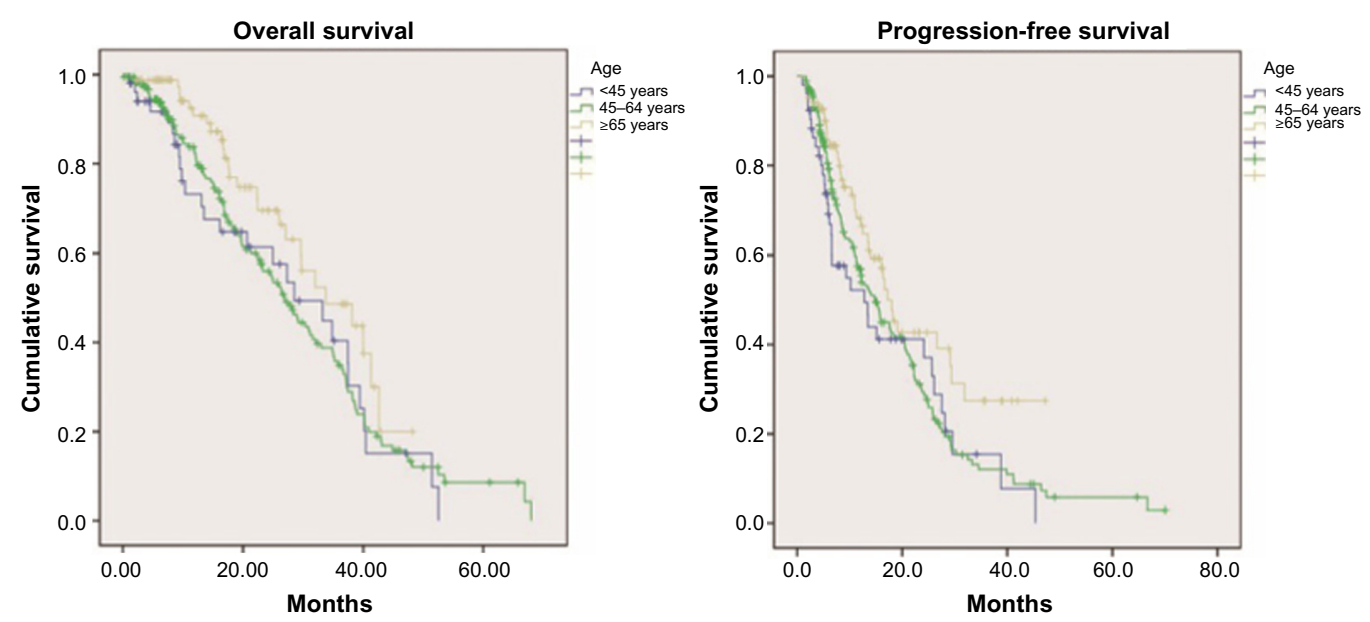

Figure I Kaplan-Meier curves of overall survival and progression-free survival among the young, middle-aged and old groups.

Note: There were no significant differences among young, middle-aged, and old groups in terms of overall survival $(P=0.087)$, whereas progression-free survival in the old group was significantly better than in the young and middle-aged groups $(P=0.043)$. 

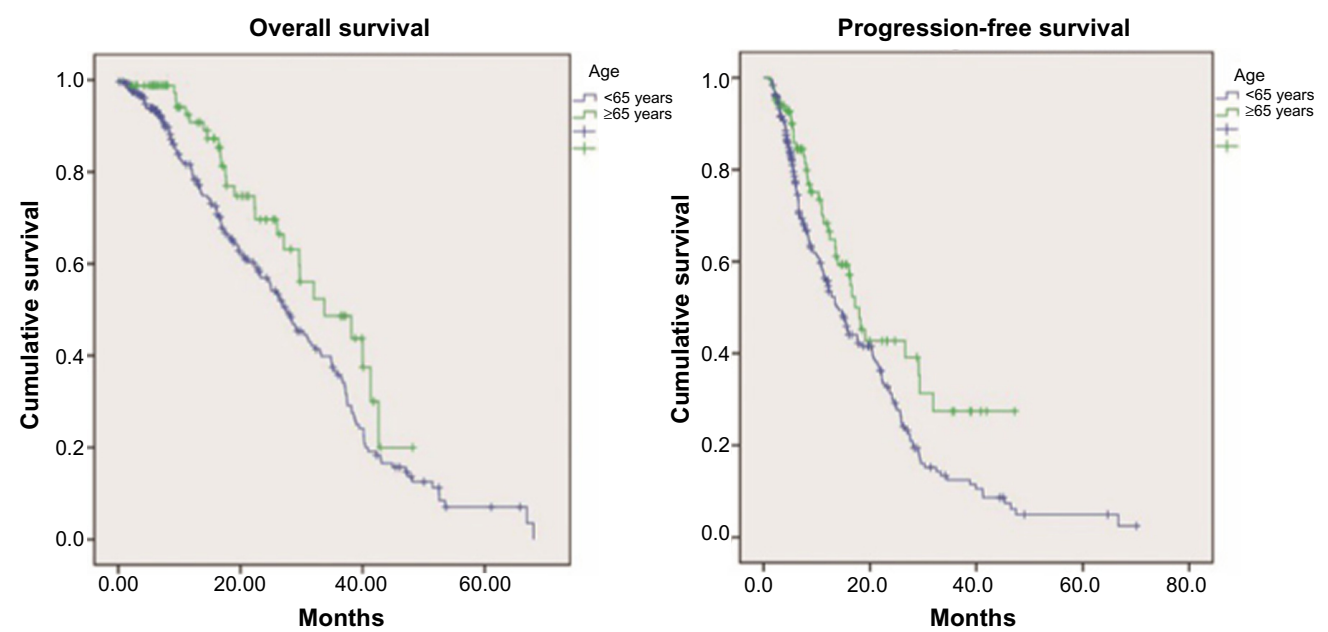

Figure 2 Kaplan-Meier curves of overall survival and progression-free survival in old and younger groups.

Note: Both overall survival $(P=0.029)$ and progression-free survival $(P=0.015)$ in the younger group were significantly worse than in the old group.

interval, 0.329-0.828; $P=0.006]$; PFS: hazard ratio, 0.584 [95\% confidence interval, $0.401-0.850 ; P=0.005]$ ).

\section{Discussion}

In this retrospective study, conducted in two clinical centers in Eastern China, we revealed a favorable prognosis in old patients with advanced RCC and $\mathrm{mRCC}$ who received targeted therapy. OS and PFS in old patients (aged $\geq 65$ years) were significantly better than that in younger patients (aged $<65$ years), whereas there was no notable difference in OS and PFS between young (aged $<45$ years) and middleaged (aged 45-64 years) patients.

Targeted therapy has changed the intervention strategy for mRCC since 2005, when targeted agents were approved by the US Food and Drug Administration. Given the incidence of RCC peaks among old people, ${ }^{6,14}$ it is important to evaluate these patients thoroughly and to choose proper treatment. However, little information about the efficacy and safety of targeted agents in old mRCC patients was supplied in clinical trials because relatively fewer old patients were enrolled for various reasons, such as greater prevalence of comorbidity and poorer baseline organ function. Therefore, paucity of clinical evidence and concerns about toxicity and intolerance in old patients might restrict the scope of targeted therapy. To date, only two studies were conducted to compare the clinical outcomes of targeted agents between old and young RCC patients. Eisen and colleagues have analyzed the data from a phase 3 clinical trial and found that outcomes of older and younger patients with advanced RCC treated with sorafenib were similar and had predictable and manageable adverse events. ${ }^{13}$ OS was not documented by the authors, who only assessed the difference in PFS
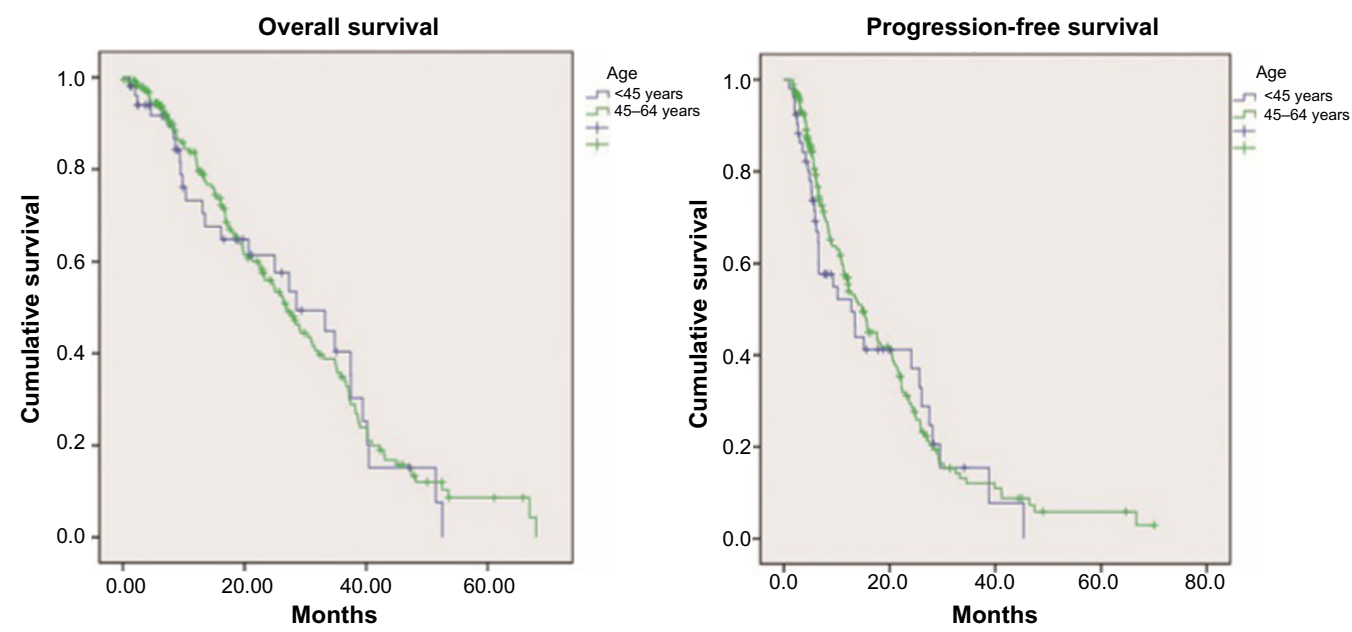

Figure 3 Kaplan-Meier curves of overall survival and progression-free survival in young and middle-aged groups.

Note: There were no significant differences between young and middle-aged groups regarding overall survival and progression-free survival. 


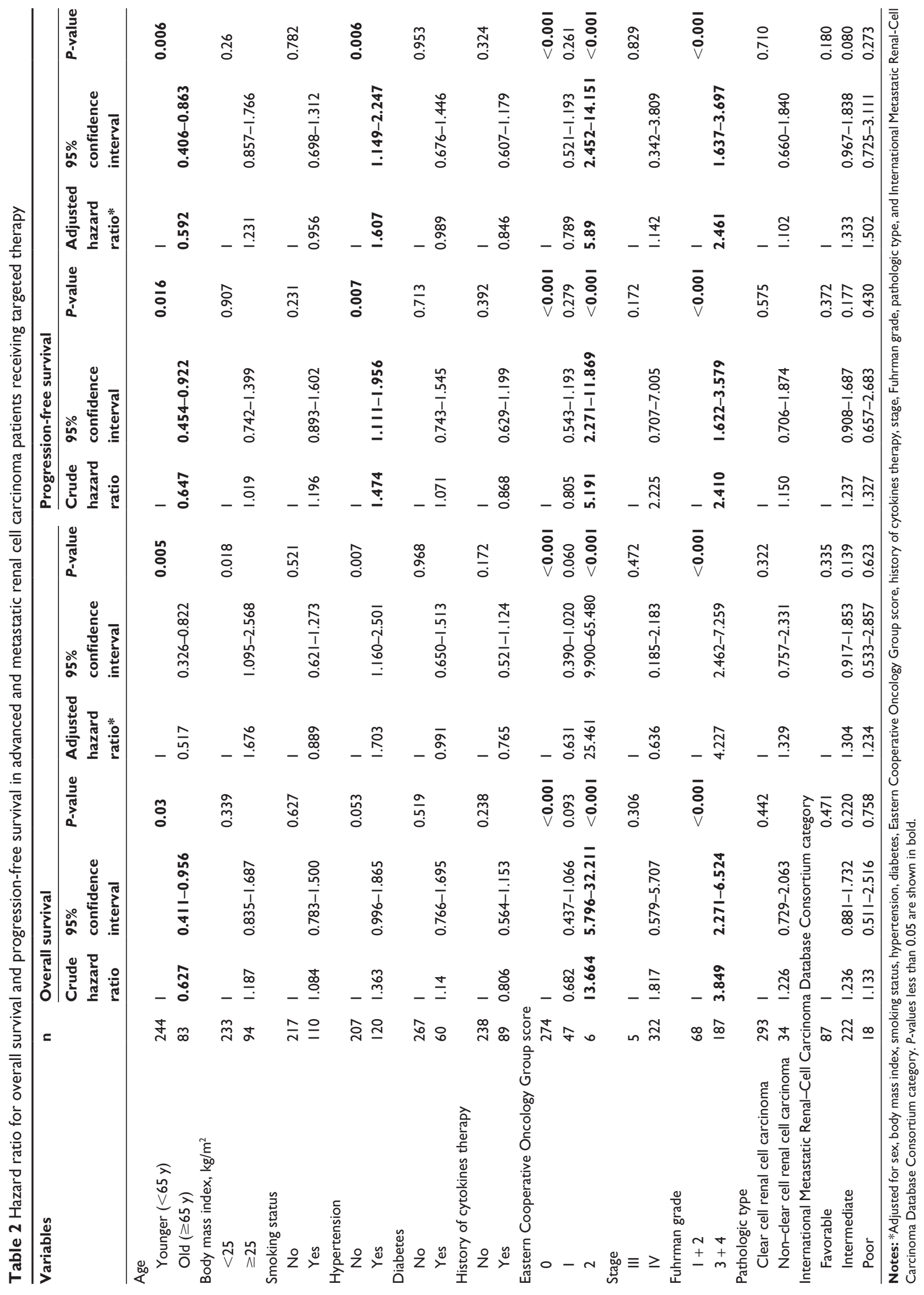


between old and young patients. During our preparation for this study, another retrospective data analysis from six trials revealed a slightly better, but not significant, median PFS (11.0 vs 9.9 months) and median OS (25.6 vs 23.6 months) in older, as opposed to younger, mRCC patients receiving first-line sunitinib treatment. Adverse effects occurred more often in older than in younger patients. ${ }^{12}$ Likewise, our study found that older patients with advanced RCC and mRCC in the People's Republic of China could benefit from targeted therapy, with even better clinical outcomes. Both OS and PFS were notably prolonged, whereas adverse events did not clearly increase. Intriguingly, the favorable outcomes were observed only in patients aged 65 years or older compared with younger patients. There was no significant difference between young and middle-aged patients with respect to OS, PFS, and adverse effects.

Together with the two aforementioned studies, our results raise the possibility that antiangiogenic agents may be more effective for old patients with advanced RCC and mRCC. Although the studies had conflicting results, the clinicopathological features of RCC were age-dependently different. Observations from several studies have shown that early-stage RCC decreases with increasing age, and that young patients are more likely to present with relatively favorable histology, suggesting that RCC in younger patients does not behave biologically in a more aggressive manner. ${ }^{8,10,14,15}$ It is known that RCC is characterized by abundant vasculature, and age-related discrepancy in cancer vasculature has been observed through tumor biopsy. Meehan et al have investigated the influence of age on structural and molecular traits, focusing on RCC vasculature, and have found that microvascular density is dramatically higher in old clear cell RCC patients (aged $\geq 65$ years) than in their younger counterparts. ${ }^{16}$ Experimental results from mouse xenograft models have indicated that old mice respond better than young ones to antiangiogenic treatment. ${ }^{17}$ Therefore, we speculate that old patients have a favorable prognosis with targeted therapy that might be ascribed to different tumor vasculature, of which higher microvascular density represents an important feature.

Several studies have found better OS and PFS in East Asian mRCC patients, using targeted agents, compared with corresponding international studies. ${ }^{18-21}$ Similar results were observed in the present study for both OS and PFS. Although the underlying mechanism regarding the discrepancy of response to targeted agents among different ethnic backgrounds is still a subject of research, race-dependent variation in clinicopathological characteristics and molecular targets is known. For example, RCC patients from white, African-American, Hispanic, and Asian backgrounds have different symptoms, disease course, and clinical outcomes after standard treatment. ${ }^{22}$ Gene polymorphism may also explain the disparity of response and tolerability in RCC patients receiving targeted therapy. ${ }^{23}$ However, further studies of the exact mechanism are still warranted.

Several limitations in the present study are worth mentioning. First and foremost, the patients included in this study received different first-line targeted therapy. Some of them took different second-line agents after first-line therapy failed, whereas others did not. In addition, some had a history of cytokine therapy. The disparity in therapeutic strategy might have a confounding effect on the results. Second, several well-known factors affecting the outcome of RCC such as lactic dehydrogenase and time from diagnosis to treatment were not considered, which might also have resulted in an unbalanced baseline. Third, histopathological types differed among the three groups, although clear cell RCC accounted for more than $80 \%$ of cases. It is hard to illustrate the extent to which different histopathological types contributed to the different responses to targeted agents. Finally, our data were subject to the inherent bias of the retrospective nature of the study and the relatively small sample size. Nevertheless, this is believed to be the first study conducted in the Chinese population to provide additional data on the relationship between age and targeted therapy.

In conclusion, old age is a favorable prognostic factor for advanced RCC and $\mathrm{mRCC}$ patients receiving targeted therapy. Prolonged OS and PFS were observed in old patients (aged $\geq 65$ years) compared with younger ones (aged $<65$ years), whereas there was no significant difference between young (aged $<45$ years) and middle-aged (aged $45-64$ years) patients. Adverse effects were comparable among patients with different age levels. Further prospective studies based on a large population are warranted.

\section{Acknowledgment}

Supported by the National Natural Science Foundation of China (Grant NSFC 81001131).

\section{Disclosure}

The authors report no conflicts of interest in this work.

\section{References}

1. Gupta K, Miller JD, Li JZ, Russell MW, Charbonneau C. Epidemiologic and socioeconomic burden of metastatic renal cell carcinoma (mRCC): a literature review. Cancer Treat Rev. 2008;34(3):193-205.

2. Athar U, Gentile TC. Treatment options for metastatic renal cell carcinoma: a review. Can J Urol. 2008;15(2):3954-3966. 
3. Fyfe GA, Fisher RI, Rosenberg SA, Sznol M, Parkinson DR, Louie AC. Long-term response data for 255 patients with metastatic renal cell carcinoma treated with high-dose recombinant interleukin-2 therapy. J Clin Oncol. 1996;14(8):2410-2411.

4. Leibovich BC, Blute ML, Cheville JC, et al. Prediction of progression after radical nephrectomy for patients with clear cell renal cell carcinoma: a stratification tool for prospective clinical trials. Cancer. 2003;97(7):1663-1671.

5. Karakiewicz PI, Jeldres C, Suardi N, et al. Age at diagnosis is a determinant factor of renal cell carcinoma-specific survival in patients treated with nephrectomy. Can Urol Assoc J. 2008;2(6):610-617.

6. Taccoen X, Valeri A, Descotes JL, et al; Oncology Committee of the Association Française d'Urologie. Renal cell carcinoma in adults 40 years old or less: young age is an independent prognostic factor for cancer-specific survival. Eur Urol. 2007;51(4):980-987.

7. Jung EJ, Lee HJ, Kwak C, Ku JH, Moon KC. Young age is independent prognostic factor for cancer-specific survival of low-stage clear cell renal cell carcinoma. Urology. 2009;73(1):137-141.

8. Jun C, Zhishun X, Xianzhou J, Qiang F, Jin W. Association between age and clinical characteristics of renal cell carcinoma in adult patients. Int J Urol. 2006;13(5):515-519.

9. Sánchez-Ortiz RF, Rosser CJ, Madsen LT, Swanson DA, Wood CG. Young age is an independent prognostic factor for survival of sporadic renal cell carcinoma. J Urol. 2004;171(6 Pt 1):2160-2165.

10. Thompson RH, Ordonez MA, Iasonos A, et al. Renal cell carcinoma in young and old patients - is there a difference? J Urol. 2008;180(4): 1262-1266.

11. Scoll BJ, Wong YN, Egleston BL, Kunkle DA, Saad IR, Uzzo RG. Age, tumor size and relative survival of patients with localized renal cell carcinoma: a surveillance, epidemiology and end results analysis. J Urol. 2009;181(2):506-511.

12. Hutson TE, Bukowski RM, Rini BI, et al. Efficacy and safety of sunitinib in elderly patients with metastatic renal cell carcinoma. Br J Cancer. 2014;110(5):1125-1132.

13. Eisen T, Oudard S, Szczylik C, et al; TARGET Study Group. Sorafenib for older patients with renal cell carcinoma: subset analysis from a randomized trial. J Natl Cancer Inst. 2008;100(20):1454-1463.
14. Gillett MD, Cheville JC, Karnes RJ, et al. Comparison of presentation and outcome for patients 18 to 40 and 60 to 70 years old with solid renal masses. J Urol. 2005;173(6):1893-1896.

15. Verhoest G, Veillard D, Guillé F, et al. Relationship between age at diagnosis and clinicopathologic features of renal cell carcinoma. Eur Urol. 2007;51(5):1298-1304.

16. Meehan B, Appu S, St Croix B, Rak-Poznanska K, Klotz L, Rak J. Age-related properties of the tumour vasculature in renal cell carcinoma. BJU Int. 2011;107(3):416-424.

17. Kaptzan T, Skutelsky E, Itzhaki O, et al. Efficacy of anti-angiogenic treatment of tumors in old versus young mice. Mech Ageing Dev. 2006;127(4):398-409.

18. Tomita Y, Shinohara N, Yuasa T, et al. Overall survival and updated results from a phase II study of sunitinib in Japanese patients with metastatic renal cell carcinoma. Jpn J Clin Oncol. 2010;40(12): 1166-1172.

19. Shi GH, Ye DW, Yao XD, et al. Clinical efficacy and tolerance of sunitinib in the treatment of advanced renal cell carcinoma. China $J$ Urol. 2011;32(6):423-426. Chinese.

20. Motzer RJ, Hutson TE, Tomczak P, et al. Overall survival and updated results for sunitinib compared with interferon alfa in patients with metastatic renal cell carcinoma. J Clin Oncol. 2009;27(22):3584-3590.

21. Motzer RJ, Hutson TE, Tomczak P, et al. Sunitinib versus interferon alfa in metastatic renal-cell carcinoma. $N$ Engl J Med. 2007;356(2): 115-124.

22. Stafford HS, Saltzstein SL, Shimasaki S, Sanders C, Downs TM, Sadler GR. Racial/ethnic and gender disparities in renal cell carcinoma incidence and survival. J Urol. 2008;179(5):1704-1708.

23. Garcia-Donas J, Esteban E, Leandro-García LJ, et al. Single nucleotide polymorphism associations with response and toxic effects in patients with advanced renal-cell carcinoma treated with first-line sunitinib: a multicentre, observational, prospective study. Lancet Oncol. 2011;12(12):1143-1150. 


\section{Supplementary material}

Table SI Demographic and clinical characteristics between younger and old groups in advanced and metastatic renal cell carcinoma patients

\begin{tabular}{|c|c|c|c|}
\hline Variables & $\begin{array}{l}\text { Young ( }<45 \text { years) } \\
(n=244) \\
n(\%)\end{array}$ & $\begin{array}{l}\text { Old ( } \geq 65 \text { years }) \\
(n=83) \\
n(\%)\end{array}$ & $P$-value \\
\hline \multicolumn{4}{|l|}{ Gender } \\
\hline Male & $172(70.5)$ & $70(84.3)$ & 0.013 \\
\hline Female & $72(29.5)$ & $13(15.7)$ & \\
\hline BMI $\left(\mathrm{kg} / \mathrm{m}^{2}\right)$ & & & 0.602 \\
\hline$<25$ & $172(70.5)$ & $61(73.5)$ & \\
\hline$\geq 25$ & $72(29.5)$ & $22(26.5)$ & \\
\hline Smoking status & & & 0.172 \\
\hline Yes & $77(31.6)$ & $33(39.8)$ & \\
\hline No & $167(68.4)$ & $50(60.2)$ & \\
\hline Hypertension & & & 0.144 \\
\hline Yes & $84(34.4)$ & $36(43.4)$ & \\
\hline No & $160(65.6)$ & $47(56.6)$ & \\
\hline Diabetes & & & 0.687 \\
\hline Yes & $46(18.9)$ & $14(16.9)$ & \\
\hline No & $198(81.1)$ & $69(83.1)$ & \\
\hline History of cytokines therapy & & & 0.687 \\
\hline Yes & $65(26.6)$ & $24(28.9)$ & \\
\hline No & $179(73.4)$ & $59(7 I .1)$ & \\
\hline Eastern Cooperative Oncology Group score & & & 0.185 \\
\hline 0 & $209(85.7)$ & $65(78.3)$ & \\
\hline 1 & $32(13.1)$ & $15(18.1)$ & \\
\hline 2 & $3(1.2)$ & $3(3.6)$ & \\
\hline International Metastatic Renal-Cell & & & 0.537 \\
\hline \multicolumn{4}{|l|}{ Carcinoma Database Consortium category } \\
\hline Favorable & $68(27.9)$ & $19(22.9)$ & \\
\hline Intermediate & $164(67.2)$ & $58(69.9)$ & \\
\hline Poor & $12(4.9)$ & $6(7.2)$ & \\
\hline \multicolumn{4}{|l|}{ Pathologic type } \\
\hline Clear cell RCC & $213(87.4)$ & $80(96.4)$ & 0.120 \\
\hline Papillary RCC & $15(6.1)$ & $\mathrm{I}(\mathrm{I} .2)$ & \\
\hline Chromophobe RCC & $3(1.2)$ & $0(0)$ & \\
\hline Other & $13(5.3)$ & $2(2.4)$ & \\
\hline \multicolumn{4}{|l|}{ Stage } \\
\hline III & $3(1.2)$ & $2(2.4)$ & 0.449 \\
\hline IV & $24 \mid(98.8)$ & $81(97.6)$ & \\
\hline Fuhrman grade & & & 0.128 \\
\hline 1 & $5(2.1)$ & $2(2.4)$ & \\
\hline 2 & $38(15.6)$ & $23(27.7)$ & \\
\hline 3 & $76(31.1)$ & $25(30.1)$ & \\
\hline 4 & $70(28.7)$ & $16(19.3)$ & \\
\hline Missing & $55(22.5)$ & $17(20.5)$ & \\
\hline \multicolumn{4}{|l|}{ Metastatic site } \\
\hline Lung & $155(63.5)$ & $56(67.5)$ & 0.516 \\
\hline Bone & $60(24.6)$ & $21(25.3)$ & 0.897 \\
\hline Liver & $19(7.8)$ & $7(8.4)$ & 0.851 \\
\hline Other & $45(18.4)$ & $23(27.7)$ & 0.072 \\
\hline First line targeted agents & & & 0.093 \\
\hline Sorafenib & $133(54.5)$ & $54(65.0)$ & \\
\hline Sunitinib & III (45.5) & $29(35.0)$ & \\
\hline
\end{tabular}


Table SI (Continued)

\begin{tabular}{llll}
\hline Variables & $\begin{array}{l}\text { Young }(<\mathbf{4 5} \text { years) } \\
(\mathbf{n = 2 4 4 )}\end{array}$ & $\begin{array}{l}\text { Old ( } \geq \mathbf{6 5} \text { years) } \\
\mathbf{n}(\mathbf{n}=\mathbf{8 3})\end{array}$ \\
$\mathbf{n}(\%)$
\end{tabular}

Note: $P$-values less than 0.05 are shown in bold.

Abbreviations: BMI, body mass index; RCC, renal cell carcinoma.

\section{Publish your work in this journal}

OncoTargets and Therapy is an international, peer-reviewed, open access journal focusing on the pathological basis of all cancers, potential targets for therapy and treatment protocols employed to improve the management of cancer patients. The journal also focuses on the impact of management programs and new therapeutic agents and protocols on

\section{Dovepress}

patient perspectives such as quality of life, adherence and satisfaction. The manuscript management system is completely online and includes a very quick and fair peer-review system, which is all easy to use. Visit http://www.dovepress.com/testimonials.php to read real quotes from published authors. 